\title{
Low Birthweight Dwarfism with Asymmetry (Silver's Syndrome): Treatment with Human Growth Hormone
}

\author{
J. M. TANNER and T. J. HAM* \\ From the Department of Growth and Development, Institute of Child Health; \\ and The Hospital for Sick Children, London
}

In 1953 Silver et al. described two children with abnormally short stature who had low birthweights and congenital asymmetry, or hemihypertrophy. Silver in 1964 reviewed 29 cases (see also Reister and Scherz, 1964; Moseley, Moloshok and Freiberger, 1966). In 1954, Russell independently described 5 children with short stature and low birthweight; 2 of these had asymmetry and were clearly identical with those of Silver, while the other 3 had many of the morphological features of Silver's cases, but no asymmetry. Thus confusion has arisen, some authors regarding the two syndromes as separate, and others (e.g. Black, 1961) lumping them together.

The cardinal symptoms of Silver's syndrome are low birthweight for length of gestation (which is usually normal), short stature throughout childhood, asymmetry of the head, trunk, or limbs, with one arm or leg measurably longer or wider than the other, and short incurved 5th fingers. These features are so consistent that we think the descriptive term Silver's syndrome should only be applied to cases in which they are all present. Most of the cases have in addition a triangular face which is small in relation to the calvaria, with turned-down corners at the mouth (shark's-mouth), and relative smallness of the mandible. Some cases have syndactyly of the toes, and café-au-lait patches on the skin. Most of those in whom it has been investigated have a moderately delayed bone age (about 2 years delay when aged 5 to 10 ). The two original cases had high levels of gonadotrophins in the urine, but the majority of subsequent cases did not (see, however, Curi et al., 1967). Occasional cases have been said, on statistically questionable grounds, to have had pathologically early sexual development. Chromosomes are normal; the sex incidence is about equal. A history of maternal

Received July 8, 1968.

* Present address; Hospital for Sick Children, Toronto, Canada. difficulties during pregnancy is not essential to the diagnosis, though it may be obtained.

There were 12 cases of Russell's syndrome in the literature in 1965, analysed by Girard and Kaufmann (1965). All had the triangular face as in the Silver syndrome, with the prominent, sometimes bossed, forehead. All had retarded bone age. 9 had short 5th fingers; 6 had asymmetry. All Russell's original cases had short arms; this has apparently not been investigated in subsequent cases, nor has it been described to date in Silver's syndrome. However, it is clearly present in our cases (see Fig. 5 below). Girard and Kaufmann stress the low values of subcutaneous fat and the relative lack of muscle in Russell's syndrome; we find the same in Silver's. Though they consider the two syndromes can be clearly differentiated, especially by relative gain in weight and length, they offer no evidence for this statement. It seems to us, on the contrary, that the overlap is complete, except that asymmetry is a cardinal feature of Silver's syndrome and only described in half of the Russell cases. We are, therefore, of the opinion that asymmetry should be considered the operational divider (cf. Szalay, 1964). There is much to be said for dropping the eponyms, but the difficulty of using terms such as 'low birthweight dwarfism with or without asymmetry' is that other syndromes which include low birthweight dwarfism exist, and these would not be excluded.

\section{Definitions}

Dwarfism, low birthweight, and asymmetry are all arbitrary terms needing definition. We propose to call a child dwarfed when his height is $2.5 \mathrm{SD}$ or more below the mean height for his age. This means that $0.6 \%$ of normal children would be classified as dwarfs, on the assumption that the distribution of height at each age is truly Gaussian. (The 3rd centile, which is the lowest 


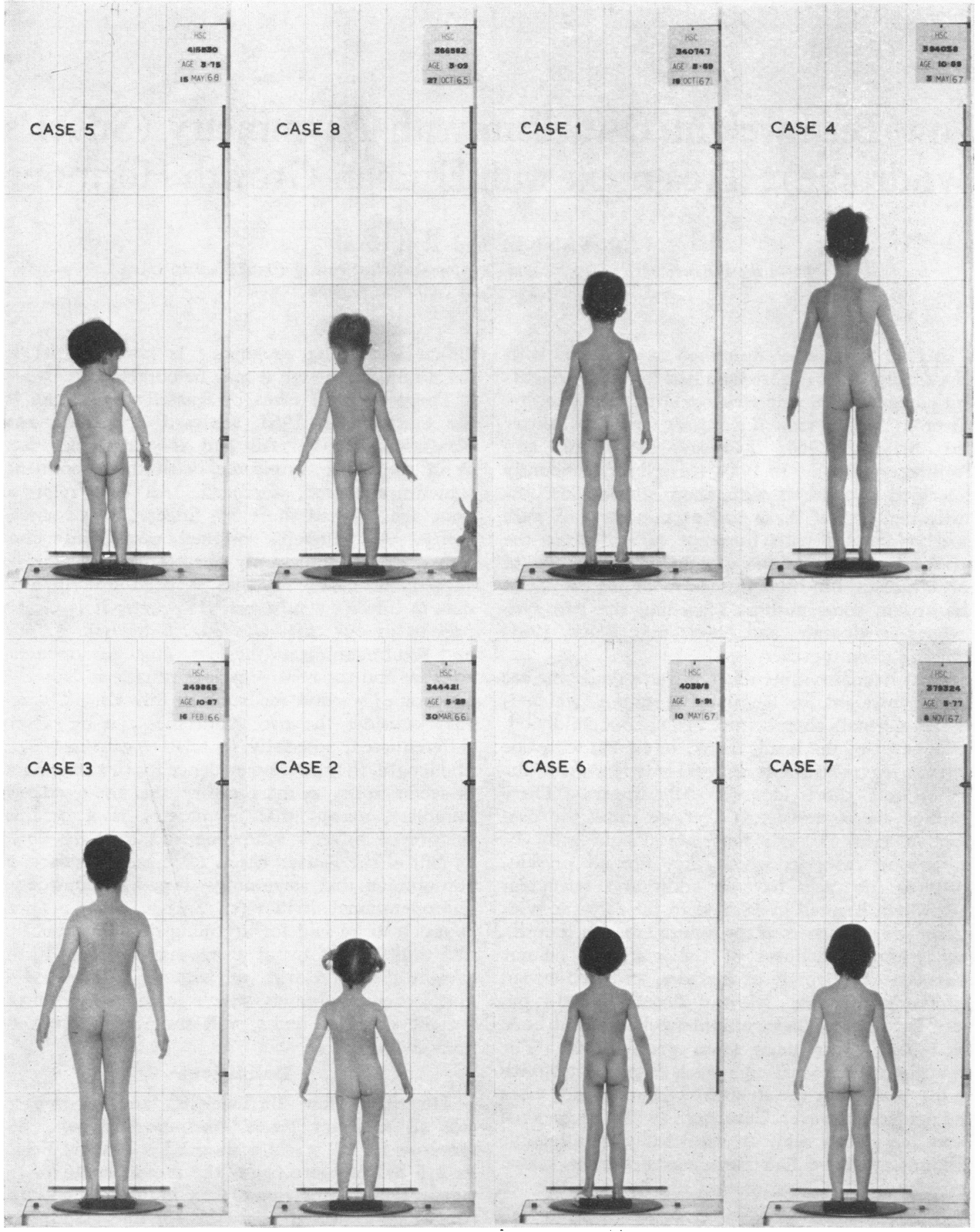

Fig. 1a.-Rear views of 8 children with Silver's syndrome. The case numbers are as in text. Note that Cases 1 and 6 have a pad placed under the shorter leg. 


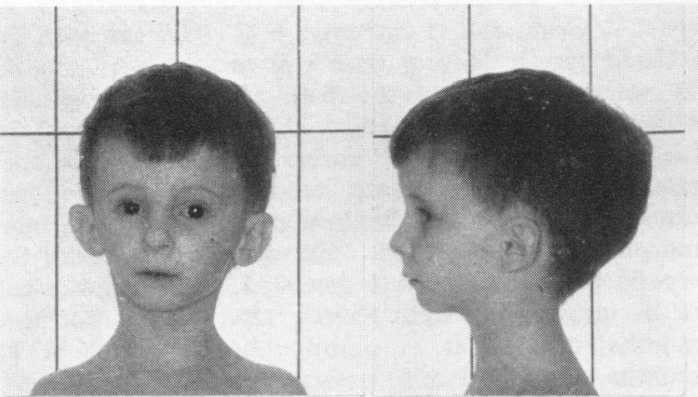

CASE 1

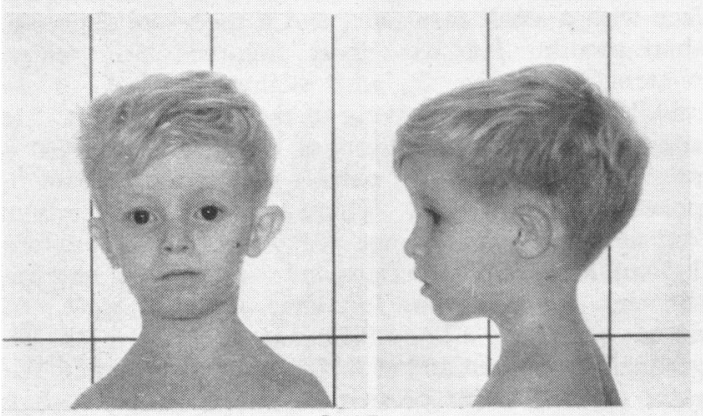

CASE 8
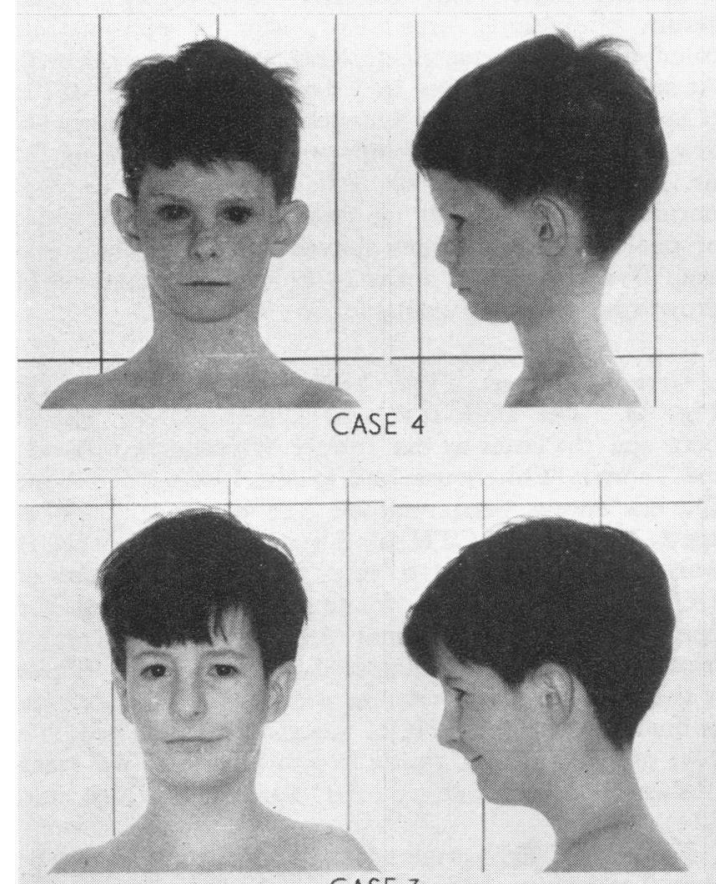

CASE 3

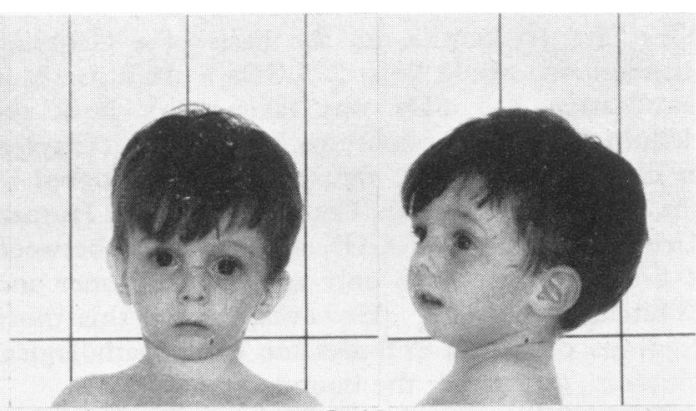

CASE 5

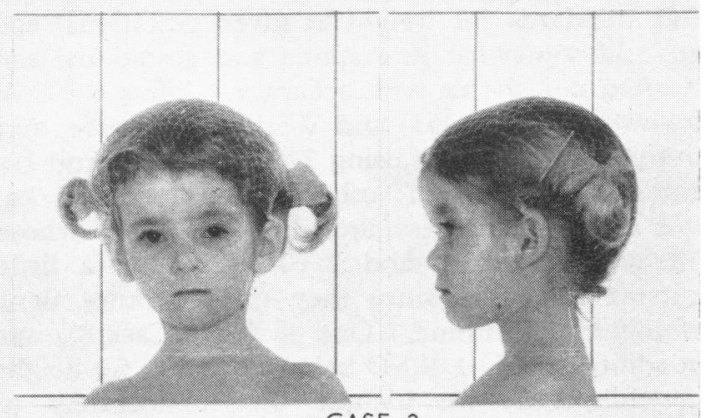

CASE 2
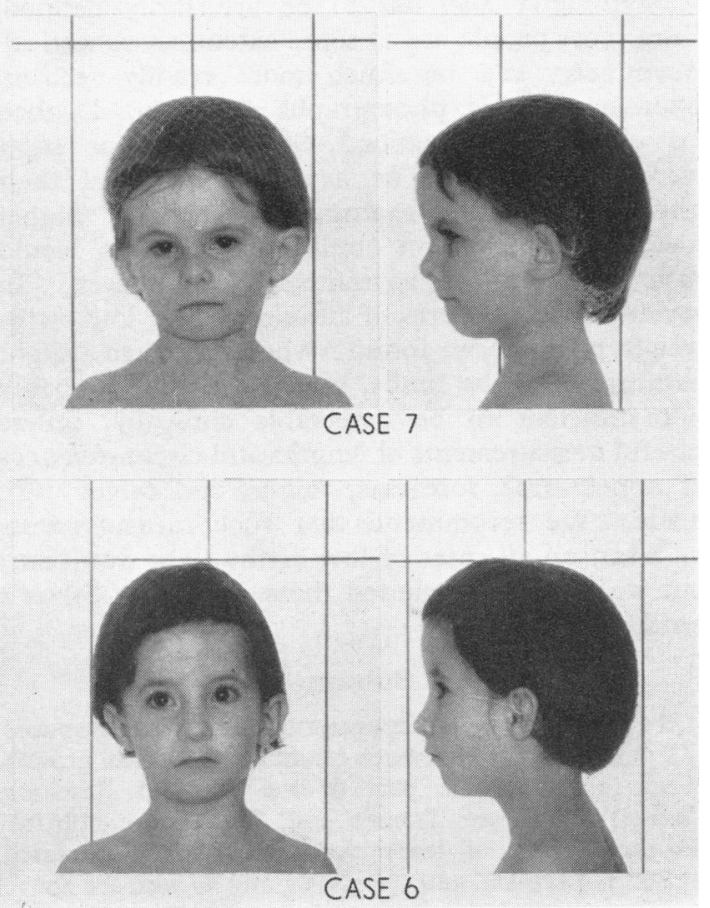

Fig. 1b.-Facial appearance of 8 children with Silver's syndrome. 
line given in the usual standard charts, is at 1.9 SDs; the 1st centile, on the basis of a Gaussian distribution, would be at $2 \cdot 3$ SDs.) In a previous publication 3.5 SDs was taken as a limit for definition of hyposomatotrophic dwarfs (Clayton et al., 1967), and this figure has been adopted in the Medical Research Council Trial of Human Growth Hormone (HGH), with children between 2.5 and 3.5 classified only as 'short' (Tanner and Whitehouse, 1967a). However, we feel this more rigorous definition excludes too many pathological children, and prefer the boundary at $2 \cdot 5$ SDs.

Low birthweight should in theory be defined in the same way, age being calculated from conception. But standards for weight at given gestational age are still somewhat in dispute, and gestational age is often not known with accuracy. Thus we have followed Black (1961) and Warkany, Monroe, and Sutherland (1961) in using $2.0 \mathrm{~kg}$. as the limit for babies born at term: other authors use $2.5 \mathrm{~kg}$. We have nevertheless included 2 children whose birthweights $(2.04$ and $2.67 \mathrm{~kg}$.) were a little outside this limit since they showed other signs of Silver's syndrome. One of them (Case 8), was in addition, only $1.9 \mathrm{SD}$ below the mean for height in childhood; we include him deliberately to underline the arbitrary nature of the limits.

Asymmetry also has to be arbitrarily defined, since most people are to some extent asymmetrical. Asymmetry can be much more readily seen in photogrammetric photographs (see Fig. 1) than on clinical examination. Several of our cases were not noted to be asymmetrical until their photographs were examined, though a higher level of suspicion on clinical examination would have resulted in asymmetry being seen. In reviewing the pictures of all our cases of low birthweight however, we found 3 who clearly had a slight asymmetry of the limbs, but of a degree probably not sufficient to be detectable clinically, unless careful measurements of lengths and circumferences of upper arms, forearms, thighs, and calves were made. We recommend that such measurements be taken on all cases of low birthweight dwarfism; but we have not included these 3 cases as Silver's syndrome here.

\section{Subjects}

We first describe the appearance and growth response of 2 children who have been treated with human growth hormone (HGH) as part of the Medical Research Council Trial (see Tanner and Whitehouse, 1967a). We then give brief descriptions of 6 further untreated children, 4 typical, and 2 (Cases 7 and 8 ) who are above our limits of birthweight and stature, but otherwise show the symptoms of Silver's syndrome.
Case 1. HSC 340747. This boy was first seen at age $1 \cdot 1$ years, and is currently $6 \cdot 4$. He was born by assisted breech delivery after a pregnancy known to be 41 weeks because of the date of a Friedman test. Mother 26, father 28, third child, others normal in height and birthweight. Father's height 90th centile, mother's 30th. Pregnancy reported normal and no unusual drugs taken. Birthweight $1.98 \mathrm{~kg}$.; placental morphology not recorded. He was in an incubator for several weeks, and growth was slow. Left leg noticed to be longer than right shortly after birth. Sat at 6 months, crawled at 11 months, began talking at 11 months. Intelligence at present appears to be normal.

His facial appearance can be seen from Fig. 1; he has low-set ears (the left larger than the right), a triangular face with a small mandible, and a moderate degree of shark-mouth. He has short incurved 5th fingers bilaterally (see Fig. 2), with slight hypoplasia of the middle phalanx and curving of the distal phalanx. In addition, a pseudo-epiphysis of the 2nd metacarpal is present bilaterally. A palmar transverse crease is present on both hands. There is partial syndactyly of 2nd and 3rd toes. At age 1.1 years, the left leg was $1.8 \mathrm{~cm}$. longer than the right and the thigh was noted as thicker. By age 3 the left knee and foot were also noted as larger. The difference in leg length has gradually increased and at 6.4 years it is $2 \cdot 8 \mathrm{~cm}$. The right testicle is not present in the scrotum which is hypoplastic.

Chromosomes were normal; blood count, sugar, serum cholesterol, urea, PBI, alkaline phosphatase, calcium, phosphorus, electrolytes, skull $x$-rays normal. At age $1 \cdot 1$ the response to 3 days' injections of ACTH (Clayton, Edwards, and Renwick, 1963) was abnormally low, the 17 -hydroxycorticoids only rising to $8.5 \mathrm{mg}$. $/ 24$ $\mathrm{hr}$. (normal is above $20 \cdot 0$ ). At age 3 , the sweat test was normal, and the 5-day fat balance normal. A series of pooled 24-hour urines showed gonadotrophins less than $0.4 \mathrm{HMG} 20 \mathrm{~A}$ units $/ 24 \mathrm{hr}$. No estimations of growth hormone are available.

Growth progress. The height chart is shown in Fig. 3a. The stars represent height plotted against bone age (the latter by the Tanner-Whitehouse method; see Tanner, Whitehouse, and Healy, 1962). The bone age has always been retarded. It was $1 \cdot 1$ 'years' at age $2 \cdot 7$ (but after ACTH); $1 \cdot 3$ 'years' at $3 \cdot 4$ when $\mathrm{HGH}$ was started, and was 4.6 'years' at 6.4 after 3 years of HGH treatment. The treatment thus restored the bone age velocity to normal (3.3 'years' in 3 years of treatment) but has not increased it beyond this. There is thus no risk that treatment will result in a reduction in final adult height. HGH was given as indicated, in a dose of 22 or 24 I.U./week in two injections per week (Raben type preparation; MRC batches R9, R10, and R11).

From the height-attained chart of Fig. 3, it can be seen that he was falling further below the 3rd centile from 1 to 3.4 years, but that $\mathrm{HGH}$ has resulted in a catch-up to the 3rd centile. At the beginning of $\mathrm{HGH}$ 


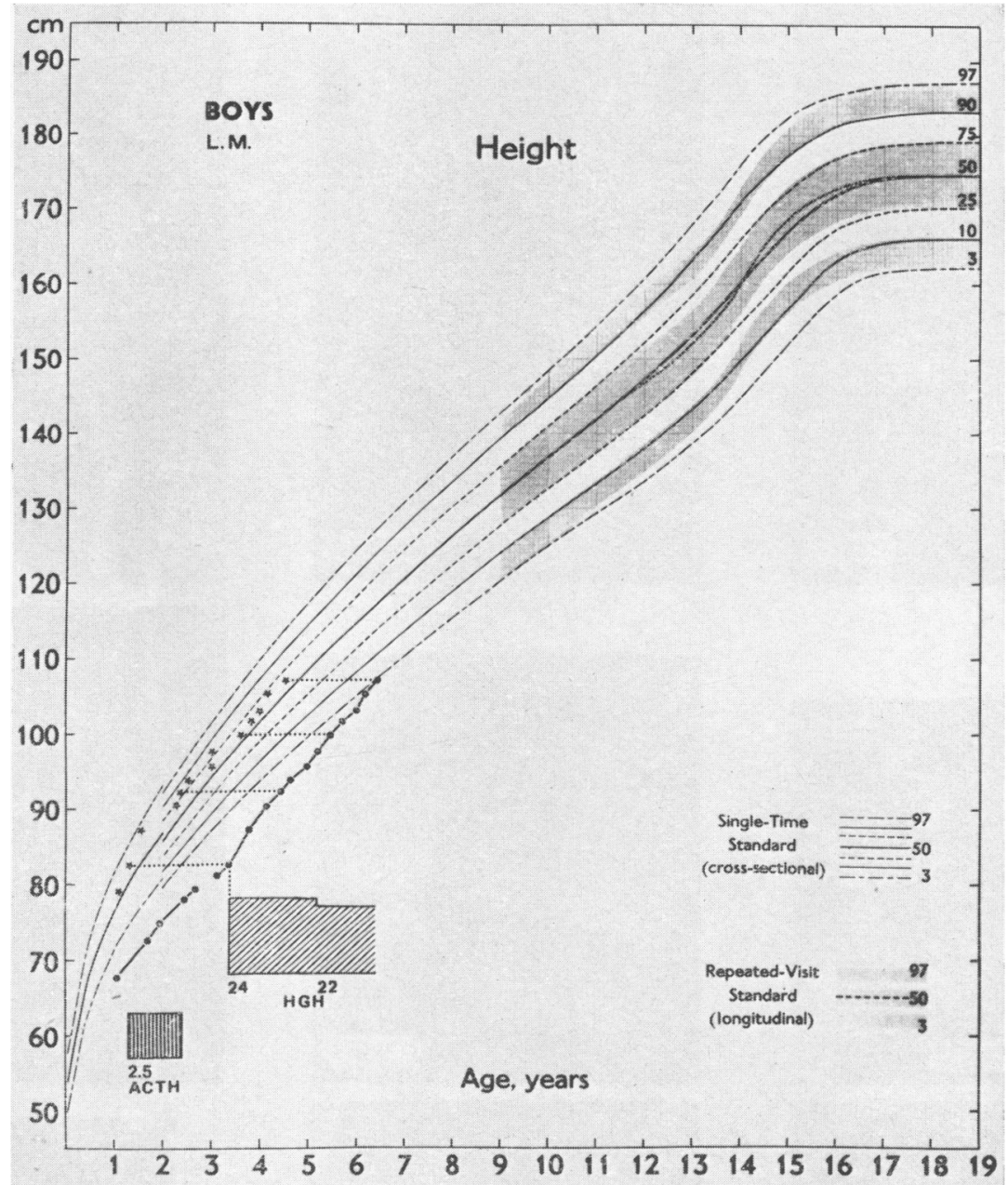

FIG. 3.-(a) Case 1, height growth. The stars represent height plotted against bone age.

treatment he was $3.6 \mathrm{SD}$ below the mean for his age and after three years of treatment only $2 \cdot 0 \mathrm{SD}$ below. The velocity chart in Fig. $3 \mathrm{~b}$ shows the details more clearly. The bars and large dots show the average rate over a year, or nearly a year; the small dots joined by the dotted line represent 3-monthly velocities, and are hence subject to seasonal fluctuations (see Tanner, Whitehouse, and Takaishi, 1966). He was at about the 5 th centile for height velocity from $1 \cdot 1$ to $1 \cdot 7$ years, then at about the 20 th till $\mathrm{HGH}$ was started at 3.4 years. ACTH, $2.5 \mathrm{U} /$ day, was given from the age of $1 \cdot 3$ to $2 \cdot 4$ years but without any significant effect upon height velocity. $\mathrm{HGH}$ caused the velocity to reach the 95 th centile $(9.0 \mathrm{~cm}$. $/ \mathrm{yr}$.) in the first year of administration, and the 85th centile in the second $(7.5 \mathrm{~cm} . / \mathrm{yr}$.$) and third (7 \cdot 1 \mathrm{~cm} . / \mathrm{yr}$.) years. The reduction in the second and third years is characteristic of all catch-up situations (Prader, Tanner, and von Harnack, 1963) and occurs also when $\mathrm{HGH}$ is given to hyposomatotrophic dwarfs (Tanner and Whitehouse, 1967a). Antibodies to $\mathrm{HGH}$ have been looked for each 3 months, but none have been found.

Skinfold measurements have been very low until recently. - The triceps fold was below the 3rd centile from $1 \cdot 1$ years to $5 \cdot 5$ years, when it rose to reach the 3rd. The subscapular fold was at about the 3rd from $1 \cdot 1$ to $2 \cdot 5$ years, then at the 5 th until $\mathrm{HGH}$ was started, and subsequently rose gradually to approximately the 25th. ACTH did not increase the amount of subcutaneous fat, and the initial injections of $\mathrm{HGH}$ did not decrease it, as they almost always do in hyposomatotrophic dwarfs who are usually fat (Tanner and Whitehouse, 1967b).

Sitting height for stature was at the 10th centile 


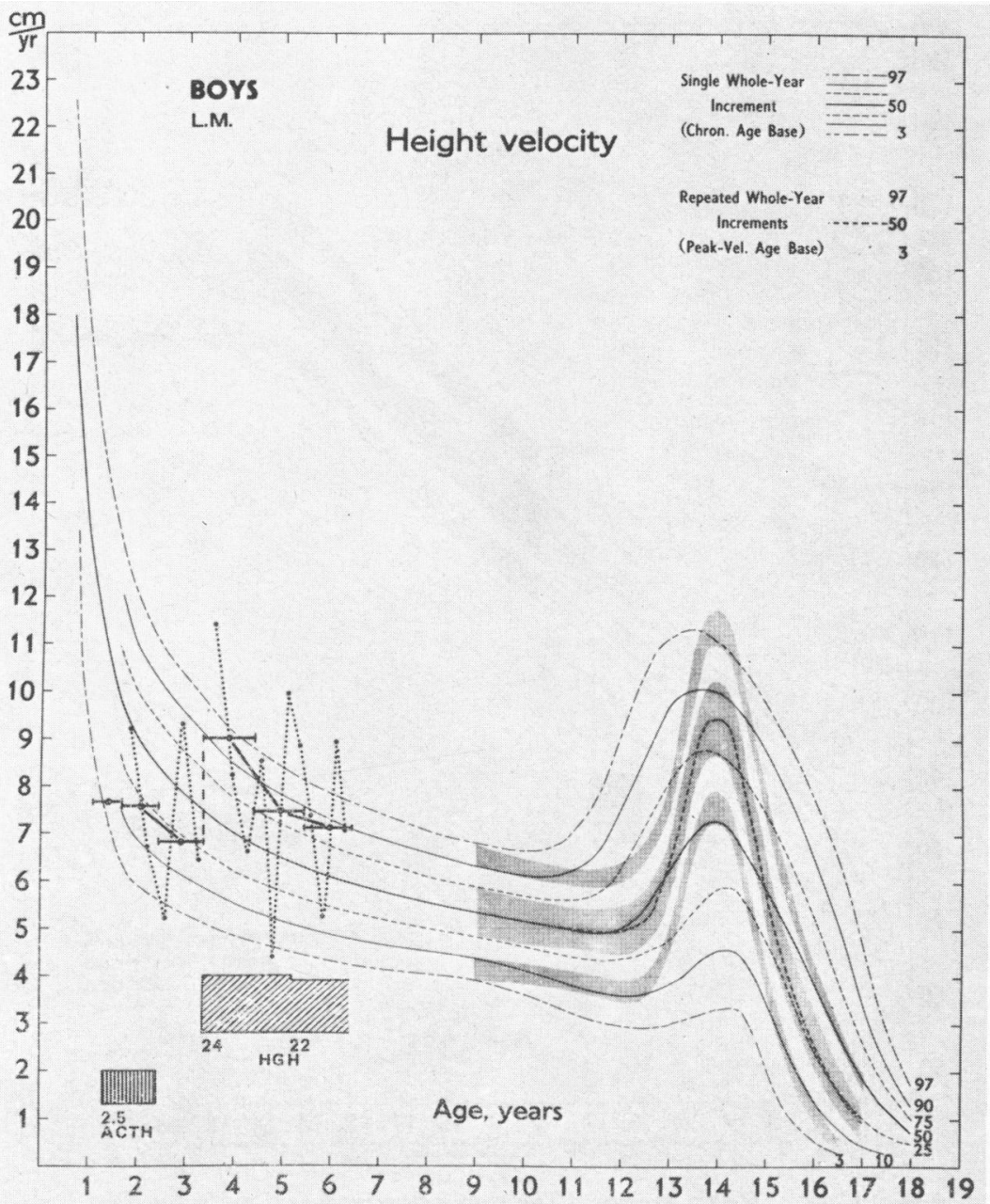

FIG. 3.-(b) Height velocity. The solid lines represent yearly velocities, the dotted lines three-monthly velocities.

when first seen, and has remained there throughout the HGH treatment.

Case 2. HSC 344421. This girl was first seen at age 1.8 years and followed in the Growth Clinic from 4.0 to her present age of $7 \cdot 8$ years. She was born at home 10 days postmature after a normal pregnancy during which no unusual drugs were taken. The placental morphology was not described. Birthweight was 1.8 kg. Both father's and mother's heights are at the 10th centile. There are 3 sibs of normal height and birthweight.

She has had eczema since the first few months of life, and mild asthma since about age 4. The eczema has needed no treatment, and the asthma only antihistamines each night since age 6 . No steroids were given until one month before the end of the period considered.
She was noted to have a palpable liver and spleen at a few months of age, but this was no longer the case at 6 years. The entire right side of the body, including the forehead, has been larger than the left since early childhood. Milestones were passed normally and her intelligence at 7 years appears to be normal.

Her facial appearance can be seen in Fig. 1. In addition to frontal bossing and the triangular face with small mandible, she has ptosis on the left side. The ears are somewhat low set, with the left lower than the right.

Her hands are shown in Fig. 2 at age 1.7 and 6.8 years. She has on both sides incurved fifth fingers, with small middle phalanges and markedly deformed and sclerotic distal phalanges. The epiphyses appear wide and sclerotic, though not so markedly as in the case described by Moseley et al. (1966) as Kirner's 


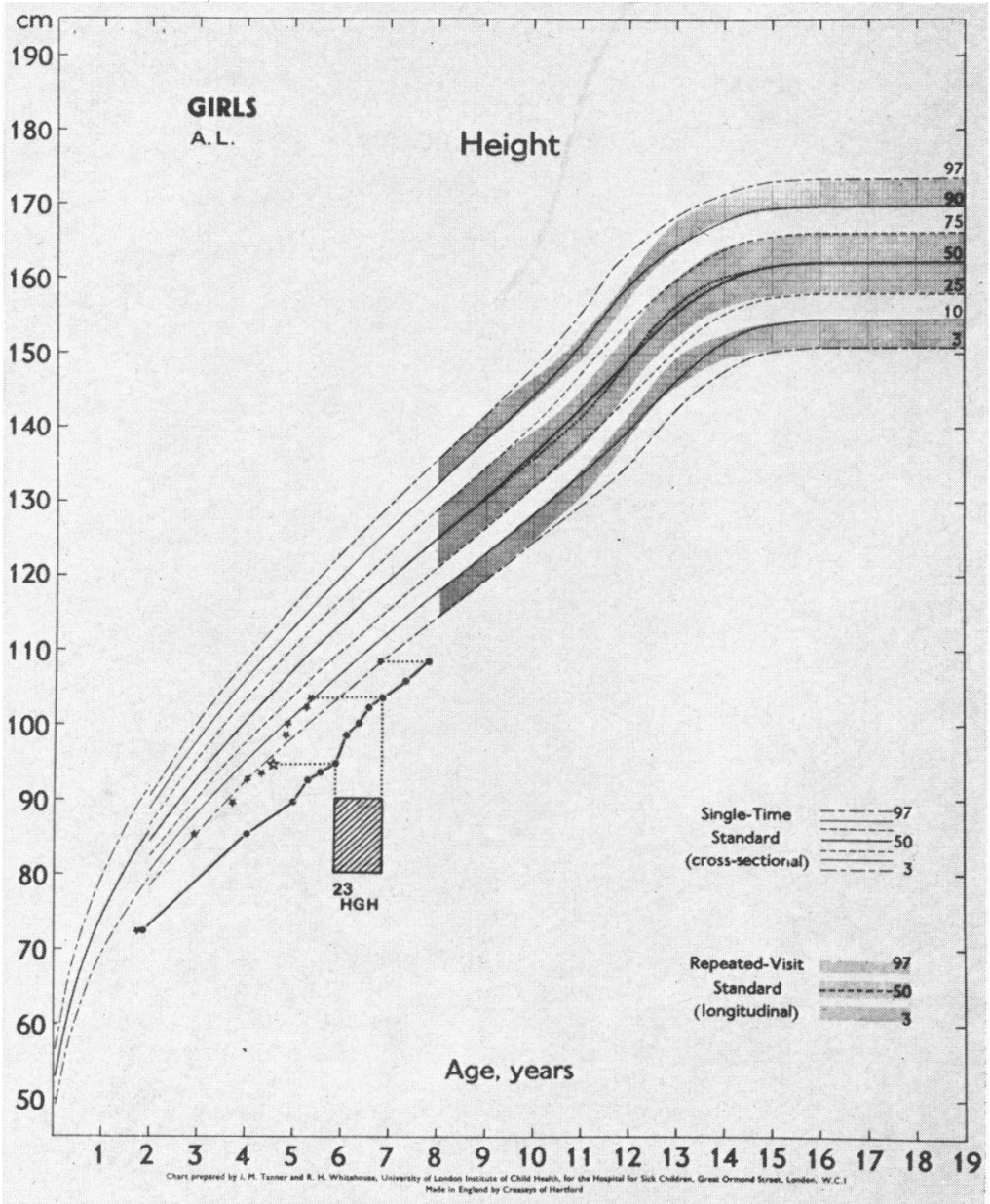

FIG. 4-(a) Case 2. Height growth. The stars represent height plotted against bone age.

deformity. A pseudo-epiphysis of the second metacarpal was present. There was genu valgus and pes valgus. At age 1.8 years the right leg was $1.3 \mathrm{~cm}$. longer than the left.

Sex chromatin was positive: blood count, sugar, serum cholesterol, urea, PBI, electrolytes, urine amino acid and sugar chromatography, and a 5-day fat balance were normal. In pooled 24-hour urines the mean gonadotophin excretion was less than 0.4 HMG $20 \mathrm{~A}$ units per 24 hour. The 17-hydroxycorticosteroids showed a normal response $(26 \mathrm{mg}$.) to 3 days of injection of ACTH. 17-ketosteroids were normal. Plasma growth hormone by radioimmunoassay was $12.0 \mathrm{ng}$./ ml. one hour after food, and $5.5 \mathrm{ng} . / \mathrm{ml}$. $17 \frac{1}{2}$ hours after food. Metabolic balance was carried out before treatment with HGH. There was a significant fall in blood urea and urine nitrogen after $\mathrm{HGH}$ administration, and increased urinary excretion of calcium. Two low birthweight dwarfs without asymmetry studied similarly showed similar results.

Growth progress. Height-attained and height velocity charts are shown in Fig. 4a and b. Since age 4.0 her bone age has been about $1 \frac{1}{2}$ years retarded. HGH (MRC batches R8 and R10) was given from age 5.8 to 6.8 years in a dose of $23 \mathrm{I}$.U./week divided into 2 injections each week. At the beginning of treatment she was 3.4 SDs below the mean height for her age, and at the end had caught up to $2 \cdot 7 \mathrm{SDs}$ below. At the end of a further year without treatment she was 3.0 SDs below. Her velocity chart shows her yearly velocity before $\mathrm{HGH}$ to be at the 5th then 25 th centile, while on HGH it was above the 97 th centile $(8 \cdot 6 \mathrm{~cm}$. yr.). In the post-treatment year it fell aga $n$ to the 25 th centile. The immediate response to $\mathrm{HGH}$ in the first quarter year was a velocity of $14 \cdot 8 \mathrm{~cm}$. $/ \mathrm{yr}$., 


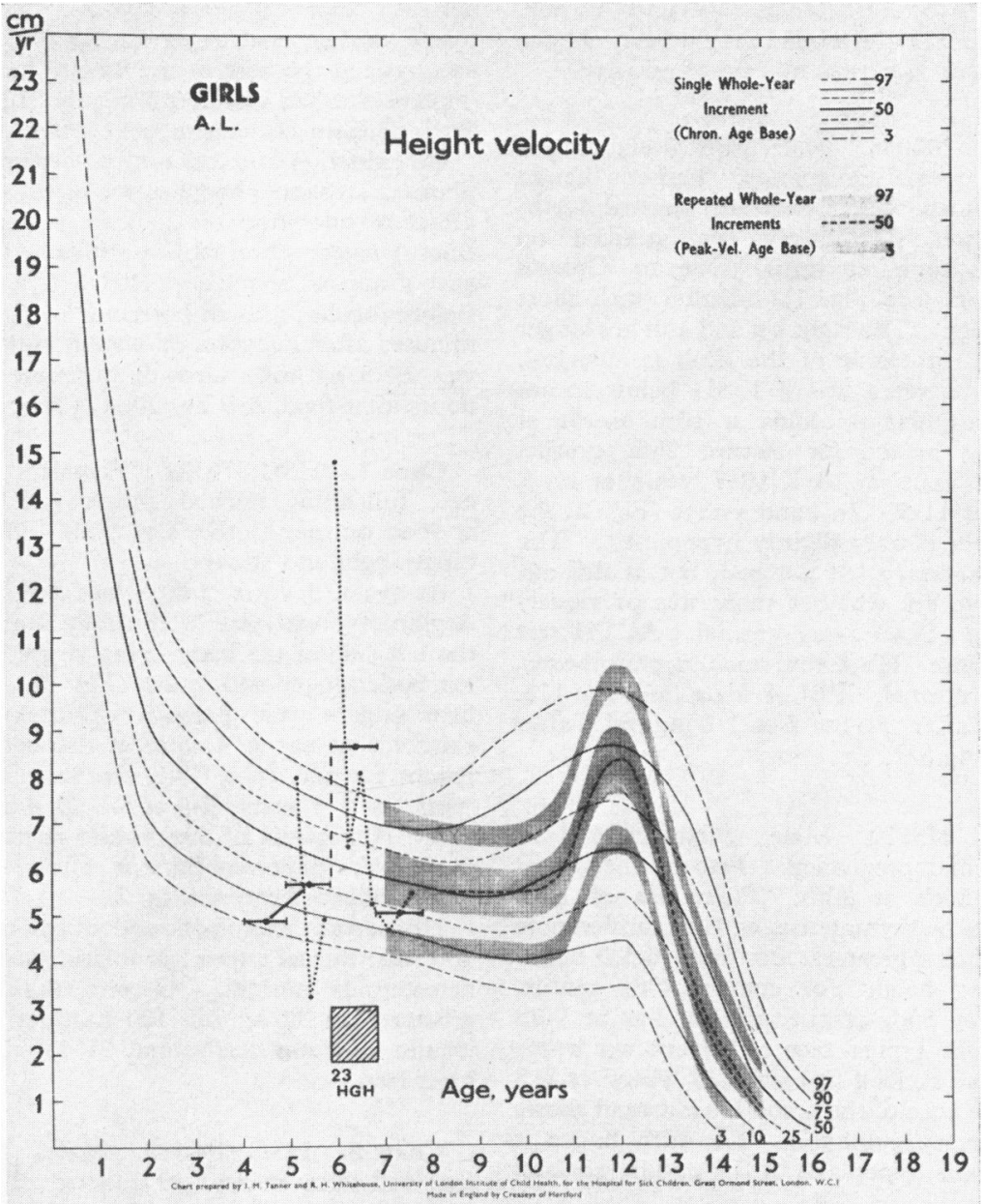

Fig. 4.-(b) Height velocity. The solid lines represent yearly velocities, the dotted lines three-monthly velocities.

which is comparable with the best responses of hyposomatotrophic dwarfs. No antibodies to HGH appeared.

Triceps skinfold measurement rose on initial treatment with $\mathrm{HGH}$ from the 50th to the 75 th centile; the subscapular fold rose from the 7th to the 60th. Triceps subsequently fell to the 40 th centile at the end of the treatment year, and subscapular fell to the 35th. Thus the skinfold response to treatment was the opposite of that seen in hyposomatotrophic dwarfs.

Sitting height for stature was at the 25th centile before treatment and remained there during treatment.

Case 3. HSC 249865. Male. Birthweight $1.47 \mathrm{~kg}$. at full term after normal pregnancy. Noted at birth to have bilaterally incurved 5 th fingers, syndactyly of 3 rd and 4th fingers on right side, an unusually long head, and café-au-lait patches on both legs. Father's height 25 th centile, mother's 35th. 3 sibs normal in birthweight and stature. Asymmetry first noticed in routine whole-body photograph taken at initial visit to Growth Clinic at age 10.9 years (see Fig. 1). The right arm is longer than the left; the right limb circumferences are greater; stance is asymmetrical. Stature at age 10.9 was $2.5 \mathrm{SDs}$ below the mean. Bone age was $1 \cdot 1$ 'years' at chronological age of 1.5 years; 1.6 at $2.4 ; 2.3$ at $3.3 ; 7.7$ at 8.5 ; and 11.4 at 10.9 (see Fig. 2). There was triquetral-lunate fusion and minimal ulnar and radial notching at the base of the 2nd metacarpal, but no pseudoepiphysis. Triceps and subscapular skinfolds at age 10.9 were at the 90th centile. Sitting height for stature 50th centile. Skull $x$-ray normal. $\mathrm{Hb}$, serum calcium, phosphorus, urea, electrolytes, normal. PBI $5 \cdot 8 \mu \mathrm{g} . / \mathrm{ml}$. Growth hormone after $3 \frac{1}{2}$-hour fast $3.0 \mathrm{ng}$./ml.; after $17 \frac{1}{2}$-hour fast $7.4 \mathrm{ng} . / \mathrm{ml}$. At age 8.5 two separate collections of pooled 24-hour urines showed the mean gonado- 
trophin excretion to be $0.35 \mathrm{HMG} 20 \mathrm{~A}$ units in one, and less than $0.2 \mathrm{HMG} 20 \mathrm{~A}$ units in the other. At age $10 \cdot 9$, when last seen, there was no sign of puberty.

Case 4. HSC 394038. Male. Birthweight $1 \cdot 84$ kg. at full term, normal pregnancy. Father's height 40th centile, mother's 50th. One sib, normal birthweight and stature. Asymmetry first noticed on whole-body photograph at initial visit to Growth Clinic at 10.0 years (see Fig. 1), together with short incurved fifth fingers. The right leg and arm are longer than the left; the right side of the skull is enlarged. Stature at age 11.8 years was 3.1 SD below mean. Triceps and subscapular skinfolds at 10th centile at age $10 \cdot 0$. Sitting height for stature 25th centile. Bone age was $9 \cdot 2$ 'years' at $10 \cdot 1,10 \cdot 7$ 'years' at 11.4 , and 11.4 'years' at $11 \cdot 8$. In hand $x$-rays (Fig. 2) the fifth middle phalanx is only slightly hypoplastic. The base of the 2nd metacarpal is notched, but at this age it is not possible to see whether there was previously a pseudoepiphysis. Skull $x$-ray normal. ACTH test gave a normal response. $\mathrm{Hb}$, serum calcium, phosphorus, urea, electrolytes normal. PBI $4.6 \mu \mathrm{g}$. $/ \mathrm{ml}$. IQ 116 . Growth hormone after 3-hour fast $1.0 \mathrm{ng} . / \mathrm{ml}$; after $17 \frac{1}{2}$-hour: fast $0 \cdot 8 \mathrm{ng} . / \mathrm{ml}$.

Case 5. HSC 415530. Male. Birthweight 1.98 kg., full-term normal pregnancy. Father's height at 90th centile, mother's at 30th. There are no sibs. At age 3.8 noted to be asymmetric, with circumferences of the right limbs being greater. Stature 3.6 SD below the mean. Sitting height for stature 40th centile. Triceps skinfold at 10th centile, subscapular at 90th centile. He had the typical face of Silver's syndrome (see Fig. 1b). The skeletal age was 1.9 'years' at 3.8 years of age. The base of the second metacarpal shows a true supernumerary epiphysis. The fifth finger is incurved and there is hypoplasia of the middle phalanx (Fig. 2).

Serum electrolytes, urea, calcium, phosphorus, alkaline phosphatase, and glucose tolerance test normal; PBI $5.8 \mu \mathrm{g} . / 10 \mathrm{ml}$. The level of growth hormone after 17 $\frac{1}{2}$-hour fast was $9 \cdot 7 \mathrm{ng}$./ml.; after ingestion of Bovril it rose to above $32.0 \mathrm{ng} . / \mathrm{ml}$., a normal response.

Case 6. HSC 403818. Female. Birthweight $1 \cdot 7$ kg. at full term, normal pregnancy. Father's height at 75 th centile, mother's at 70th. 2 sibs of normal stature. Asymmetry was noted by the parents at 4 months of age. At 9 months of age the right leg was $1 \cdot 3 \mathrm{~cm}$. longer and the circumference of calf and thigh $1 \cdot 3 \mathrm{~cm}$. greater than similar measurements of the left leg. Skull $x$-rays showed bulges in the right parietal and left middle fossa regions. Air encephalography, and burr hole opening of the right parietal region disclosed no abnormality.

At age 6.3 her stature was $3.6 \mathrm{SD}$ below the mean. The typical face of Silver's syndrome (see Fig. 1b), and short incurved 5th fingers were noted. Skeletal age was $2 \cdot 7$ 'years' at age 6.3 years. There was a hypoplastic middle phalanx of the 5th finger, and a pseudoepiphysis at the base of the second metacarpal (Fig. 2). Triceps skinfold was at 3rd centile, subscapular at 20th. Sitting height for stature 3rd centile.

Investigation showed normal serum, calcium, phosphorus, alkaline phosphatase, urea, and electrolytes. Glucose tolerance test, urine amino acids normal. Buccal smear chromatin positive, ACTH stimulation gave a normal response. PBI $6.5 \mu \mathrm{g} . / 100 \mathrm{ml}$., IQ 88 . Before insulin, growth hormone level $10.4 \mathrm{ng} . / \mathrm{ml}$.; 120 minutes after injection of insulin subcutaneously, level was $14.3 \mathrm{ng} . / \mathrm{ml}$. Growth hormone $13.3 \mathrm{ng} . / \mathrm{ml} .3 \frac{1}{2}$ hours after food, $6.9 \mathrm{ng} . / \mathrm{ml}$. $17 \frac{1}{2}$ hours after food.

Case 7. HSC 379324. Female. Birthweight 2.04 kg., full-term, normal pregnancy. Father's height at 90th centile, mother's at 50th. One sib of normal birthweight and stature.

At age 6.3 years stature was $3.0 \mathrm{SD}$ below mean. Asymmetry was visible clinically and in photographs, the left side of the body being larger, and left arm and leg both longer and wider (Fig. 1a). Short incurved fifth fingers were present. Triceps and subscapular skinfolds at age 6.3 were at the 80th centile; sitting height for stature at 40 th centile. Bone age was $2 \cdot 6$ 'years' at 3.3 years; 3.5 at $5.3 ; 3.9$ at 5.8 ; and 4.1 at $6 \cdot 3$. Hypoplasia of the middle phalanx and incurving of the fifth digit was present, but no pseudo-epiphysis of the 2nd metacarpal (Fig. 2).

$\mathrm{Hb}$; serum electrolytes, and urea normal; PBI $4 \cdot 7 \mu \mathrm{g}$. $100 \mathrm{ml}$; buccal smear chromatin positive. $17-\mathrm{OH}$ and ketosteroids normal. Growth hormone levels were greater than $32 \mathrm{ng} . / \mathrm{ml} .120$ minutes after injection of insulin subcutaneously, and $21 \cdot 1 \mathrm{ng} / \mathrm{ml}$. after a $17 \frac{1}{2}-$ hour fast.

Case 8. HSC 366582. Male. Birthweight $2 \cdot 67$ kg., full-term normal pregnancy. Father's height at 80th centile, mother's at 25 th. One normal older sib. Asymmetry of face and body noted at birth, the right side bing larger (see Fig. 1). At age 5.6 the right whole arm length was $1.5 \mathrm{~cm}$. greater than the left, the right leg from iliac crest to medial malleolus $1 \cdot 2$ $\mathrm{cm}$. longer, and the right upper arm and thigh circumferences each $1.0 \mathrm{~cm}$. larger. He has always been short but never below normal limits, and thus only meets the criteria of Silver's syndrome in respects other than birthweight and dwarfism. Between ages 1.6 and 5.6 years his height was at approximately the 3rd centile $(1 \cdot 8 \mathrm{SD}$ below mean at $5 \cdot 6)$. He has the typical short incurved 5th finger (see Fig. 2), with hypoplasia of the middle phalanx bilaterally and bilateral pseudoepiphyses of the second metacarpals. Bone age was $1 \cdot 5$ 'years' at $2 \cdot 6,1 \cdot 8$ at $3 \cdot 1,2 \cdot 6$ at $4 \cdot 1$, and $4 \cdot 0$ at $5 \cdot 6$. Triceps and subscapular skinfolds at the 25 th centile, sitting height for stature 50th centile. Skull $x$-ray normal. $\mathrm{Hb}$, serum calcium, phosphorus, urea, and electrolytes normal. PBI $5 \cdot 8 \mu \mathrm{g} . / 100 \mathrm{ml}$. Growth hormone has not been estimated. 


\section{Discussion}

The two children with low birthweight dwarfism with asymmetry who have been treated with $\mathrm{HGH}$ have shown a significant increase in height velocity. Whether continued treatment will result in their adult stature being within normal limits only time can show; one is still a little below the 3rd centile, after a single year's treatment, but after 3 years' treatment the other has reached the 3rd centile. This response may indicate that they suffer from a relative lack of growth hormone secretion, but at present there is no way of diagnosing this. One of the children was at least able to secrete $\mathrm{HGH}$ to a blood level of $12 \mathrm{ng} . / \mathrm{ml}$; the other was untested. Both were delayed in bone age, with a normal PBI. Neither was fat, as most hyposomatotrophic dwarfs are, and one was strikingly thin. On initial treatment their skinfolds either increased or remained constant, which is in marked contrast to the situation nearly always seen in hyposomatotrophic dwarfs. HGH restored the bone age velocity to normal, but did not increase it beyond this.

We have as yet only limited experience of the response to $\mathrm{HGH}$ of low birthweight dwarfs without asymmetry. In 3 such cases treated for one year the first responded with a velocity of $9.6 \mathrm{~cm}$./yr. compared with a pretreatment velocity of $6 \cdot 7 \mathrm{~cm}$. $/ \mathrm{yr}$. and a year's post-treatment velocity of $5.3 \mathrm{~cm} . / \mathrm{yr}$. The second had a treatment velocity of $7.6 \mathrm{~cm}$. $/ \mathrm{yr}$. compared with pretreatment of $7 \cdot 1 \mathrm{~cm}$. $/ \mathrm{yr}$. and post-treatment of $4.8 \mathrm{~cm}$. $/ \mathrm{yr}$. The third (who, however, presented a different bodily appearance from the others) had a treatment velocity of $4.8 \mathrm{~cm}$. $/ \mathrm{yr}$. compared with pretreatment of $4.8 \mathrm{~cm}$. $/ \mathrm{yr}$. and post-treatment of $3.6 \mathrm{~cm}$. $/ \mathrm{yr}$. Thus 1 of the 3 had a response comparable with that of the asymmetric cases, the second had a smaller but probably real response, and the third had little or no response.

Atout half the low birthweight dwarfs we have seen have asymmetry. Of 17 cases examined and photographed, 8 had a clinically clear asymmetry, 3 a minor asymmetry detected only on specially posed photographs, and 6 had no indications of asymmetry at all.

As for the features of the syndrome itself, the short, incurved fifth finger was present in all our 8 cases. Hypoplasia of the middle phalanx was visible in $x$-rays of all cases, strikingly in 6 , but only to a minor degree in 2 . Deformity of the distal phalanx occurred in 2 . The lesions were bilateral in all cases examined. Cone-shaped epiphyses were not seen. Out of the 7 cases with $x$-rays at a suitable age, 4 had a pseudo-epiphysis at the base of the second metacarpal, and 1 a true supernumerary epiphysis, giving a combined incidence of $71 \%$. This is the first time this has been described in Silver's syndrome. However, Lee and Garn (1967) find pseudo-epiphyses (defined by the presence of deep notches on either side of the base) in $27 \%$ of healthy white American children, and de Iturriza (1968) finds them in $13 \%$ of healthy British children. In all our pseudo-epiphyses the notching was from the ulnar side, and 2 of the 3 children who did not have the pseudo-epiphysis had an ulnar notch of smaller degree. Notching on this side occurs in about $30 \%$ of healthy children (Lee and Garn, 1967), whereas slight notching on the radial side occurs in $88 \%$. It seems, therefore, as though the process which gives rise to small or deep notching on the ulnar side occurs more usually and to a greater degree in Silver's syndrome than in normal children.

Russell described his intrauterine dwarfs as having short arms, as measured by span in relation to stature (see also Szalay, 1963). We have measured arm lengths on the photogrammetric photographs of our cases from the acromioclavicular joint to the distal skin crease at the wrist, and compared them with similar measurements in healthy children of the Harpenden Growth Study. The relation of arm length to leg length (stature less sitting height) is given in Fig. 5. Both arms were measured and the average is plotted. There appears to be significant shortening of the arms relative to the legs in all our cases. When arm length is plotted against stature, the difference from normal children becomes less; and when arm length is plotted against sitting height, the Silver's cases fall within the range of the normals. Thus both arms and trunk are small relative to the legs, and normal relative to each other. (This agrees with the sitting heightfor-stature, which in all cases was at or below the 50th centile, averaging the 35th.) The length of arms and legs is normally closely correlated in man, and the Silver's situation is very unusual; we are not aware of any other condition in which it occurs. In fetal life the upper part of the body is growing faster than the lower part and it may well be that the shortened arms and trunk reflect a growth lesion in the early to mid-fetal period, which would, relatively, spare the slower growing legs.

Skinfolds range from the 3 rd to the 90 th in our 8 cases, but in all except 2 are below the 50th centile, in contrast to those of hyposomatotrophic dwarfs. 


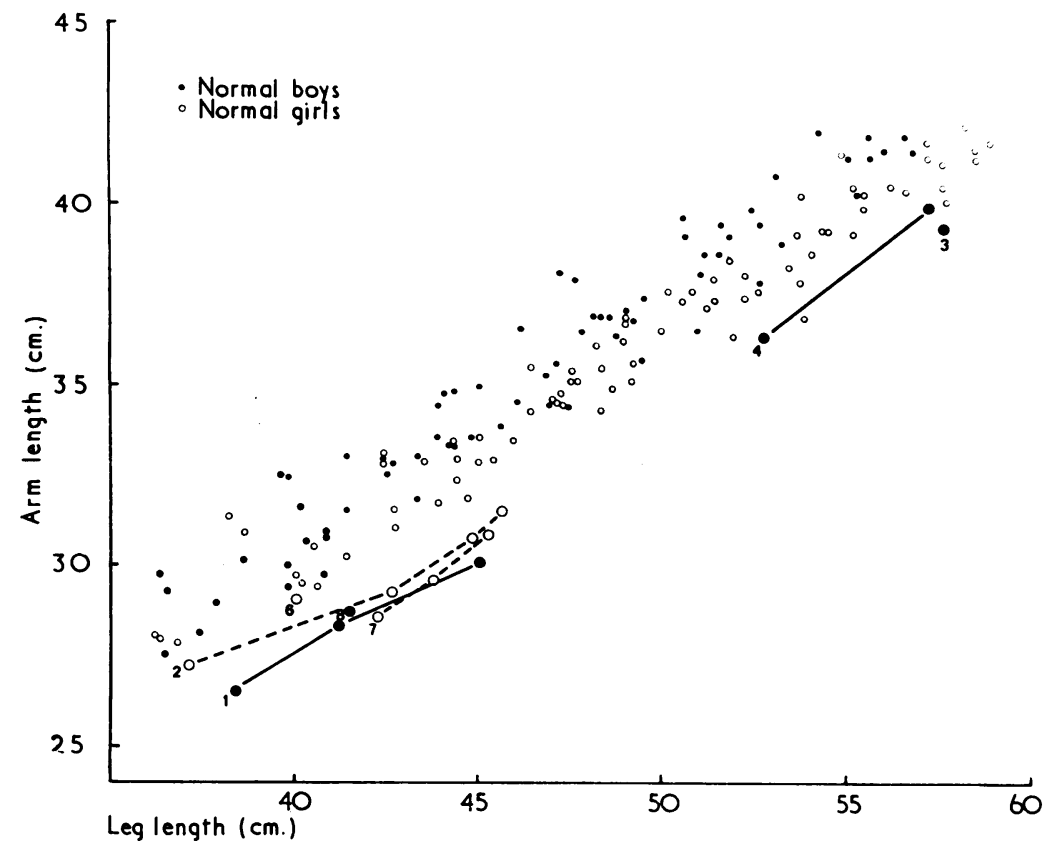

Fig. 5.-Arm length relative to leg length in Silver's syndrome (large circles), compared with normal children (small circles). The cases are numbered as in the text; successive measurements of the same child are joined. The average length of the two arms has been plotted. Leg length is taken as stature less sitting height.

The investigation of asymmetry and craniofacial disproportion of these low birthweight dwarfs has included air encephalography in several patients, including our Case 6 . Asymmetry associated with lesions of the post-central cerebral cortex was described by Penfield and Robertson in 1943, but in asymmetrical low birthweight dwarfs no cortical abnormality has been demonstrated in the cases investigated (Szalay, 1963).

The fathers' heights averaged 60th centile and the mothers' 40th centile in contrast to the low fathers' height reported by Clayton et al. (1967) in their series of low birthweight dwarfs. No sibs were affected. There seems therefore little tendency to a genetic or a consistent maternal uterine effect.

Growth hormone levels were estimated by radio-immunoassay in 5 cases. They were within normal limits at some stage during a $17 \frac{1}{2}$-hour fast in 4 cases, but low in Case 4. No further tests were available in Case 4 . Case 2 doubled her height velocity on $\mathrm{HGH}$ despite having apparently normal growth hormone levels.

Feeding difficulties in the first few months after birth were noted in 7 of the 8 cases, but no detailed account of them is available.

\section{Summary}

Six children with low birthweight dwarfism and asymmetry (Silver's syndrome) are described, and 2 with all the features of the syndrome except that either birthweight or stature were just within the lower limits of normal. In addition to the usual features, 4 had bilateral pseudo-epiphyses at the base of the second metacarpals, and 1 a true supernumerary epiphysis, signs not previously noted in this disorder.

Two of these children were treated with human growth hormone (approximately 24 I.U./week) and responded with significant increases in rate of height growth. One child was treated for one year, the other for three; the latter reached the 3rd centile.

It is proposed that the term Silver's syndrome be restricted to children of short stature (without microcephaly or other special features) who have low birthweight for the length of gestation, and measurable asymmetry of arms, legs, body, or head, with incurved 5th fingers, usually with a deformity visible on $x$-ray. The term Russell dwarf should be restricted to similar children but without asymmetry. The facial appearances are similar in the two syndromes. The arms, 
measured from shoulder to wrist, are short relative to the legs when compared with healthy children of either the same age or size. It seems that some children may exist who have somewhat low birthweights (i.e. above $2 \mathrm{~kg}$.) and are somewhat small (i.e. above the 3 rd centile) but have the other features of this syndrome; they may be examples of mild degrees of intrauterine growth pathology.

We are m sst grateful for the permission of Dr. G. Newns, Dr. P. R. Evans, Mr. D. N. Matthews, and Dr. K. Holt to study their patients, to Mr. R. H. Whitehouse for the measurements and bone maturity ratings, to Miss J. M. Harrison for measuring the photographic arm lengths, to Dr. Barbara Clayton and her staff for the biochemical investigations, and to Professor A. Prader and Dr. W. A. Marshall for helpful criticism of the manuscript. The patients treated with $\mathrm{HGH}$ formed part of the clinical trial of $\mathrm{HGH}$ conducted by the Medical Research Council, and we are grateful to the Subcommittee on Human Pituitary Hormones for permission to make this report.

\section{REFERENCES}

Black, J. (1961). Low birth weight dwarfism. Arch. Dis. Childh., 36, 633.

Clayton, B. E., Edwards, R. W. H., and Renwick, A. G. C. (1963). Adrenal function in children. Arch. Dis. Childh., 38, 49.

- Tanner, J. M., Newns, G. H., Whitehouse, R. H., and Renwick, A. G. L. (1967). Differential diagnosis of children with short stature not associated with metabolic, chromosomal, or gross nervous system defects. ibid., 42, 245.

Curi, J. F. J., Vanucci, R. C., Grossman, H., and New, M. (1967). Elevated serum gonadotrophins in Silver's syndrome. Amer. f. Dis. Child., 114, 658.

Girard, J., and Kaufmann, H. J. (1965). Der Russell-Zwerg. Eine Sonderform des Zwergwuchses bei bereits intrauterinem Wachstumsrückstand. Mschr. Kinderheilk., 113, 696.

de Iturriza, J. R. (1968). Incidencia Y Significacion de Las Epifisis en Cono. Thesis, University of Venezuela.
Lee, M. M. C., and Garn, S. M. (1967). Pseudoepiphyses or notches in the non-epiphyseal end of metacarpal bones in healthy children. Anat. Rec., 159, 263.

Moseley, J. E., Moloshok, R. F., and Freiberger, R. H. (1966). The Silver syndrome: congenital asymmetry, short stature and variations in sexual development. Roentgen features. Amer. F. Roentgenol., 97, 74.

Penfield, W., and Robertson, J. S. M. (1943). Growth asymmetry due to lesions of the postcentral cerebral cortex. Arch. Neurol. Psychiat. (Chic.), 50, 405.

Prader, A., Tanner, J. M., and von Harnack, G. A. (1963). Catchup growth following illness or starvation. f. Pediat., 62, 646.

Reister, H. C., and Scherz, R. G. (1964). Silver syndrome. A report of two cases and a review of the literature. Amer. $\mathcal{F}$. Dis. Child., 107, 410.

Russell, A. (1954). A syndrome of 'intra-uterine' dwarfism recognizable at birth with cranio-facial dysostosis, disproportionately short arms, and other anomalies (5 examples). Proc. roy. Soc. Med., 47, 1040.

Silver, H. K. (1964). Asymmetry, short stature, and variations in sexual development. Amer. F. Dis. Child., 107, 495.

—, Kiyasu, W., George, J., and Deamer, W. C. (1953). Syndrome of congenital hemihypertrophy, shortness of stature, and elevated urinary gonadotrophins. Pediatrics, 12, 368.

Szalay, G. C. (1963). Pseudohydrocephalus in dwarfs: the Russell dwarf. F. Pediat., 63, 622.

- (1964). Intrauterine growth retardation versus Silver's syndrome. ibid., 64, 234.

Tanner, J. M., and Whitehouse, R. H. (1967a). Growth response of 26 children with short stature given human growth hormone. Brit. med. F., 2, 69.

- - and - (1967b). The effect of human growth hormone on subcutaneous fat thickness in hyposomatotrophic and panhypopituitary dwarfs. F. Endocr., 39, 263.

- - - and Healy, M. J. R. (1962). A Nesv System for Estimating Skeletal Maturity from the Hand and Wrist, with Standards Derived from a Study of 2,600 Healthy British Children. Parts $I$ and II. Centre International de l'Enfance, Paris.

- - - , and Takaishi, M. (1966). Standards from birth to maturity for height, weight, height velocity, and weight velocity: British children 1965. Arch. Dis. Childh., 41, 454 and 613.

Warkany, J., Monroe, B. B., and Sutherland, B. S. (1961). Intrauterine growth retardation. Amer. F. Dis. Child., 102, 249.

Correspondence to Professor J. M. Tanner, Department of Growth and Development, Institute of Child Health, 30 Guilford Street, London W.C.1. 